\title{
EFFECT OF DIFFERENT SURFACE TREATMENT METHODS ON THE SHEAR BOND STRENGTH OF ZIRCONIA BASED RESTORATIONS
}

\author{
Mohammed H Abdel-Aziz*, Ahmed H Mohammed** and Tamer A Hamza ****
}

\begin{abstract}
Statement of the Problem: Delamination of zirconia-veneered restoration is considered to be a very common failure in clinical practice. Therefore, using a chair side intra-oral repair option may be a simple alternative method to the total replacement of the restoration and may provide a clinically-acceptable and reliable immediate solution.
\end{abstract}

Aim of the Study: This study evaluated the shear bond strength of two different repairing systems (CoJet and Ceramic repair N) of zirconia-based restorations and evaluated the effect of high and low sandblasting pressure on the shear bond strength between zirconia and composite resin.

Materials and Methods: Thirty zirconia specimens were divided into two main groups according to the repairing systems: Group CJ: CoJet $^{\mathrm{TM}}$ repairing system [chairside silica coating with $30 \mu \mathrm{m} \mathrm{SiO}_{2}+$ silanization + adhesive] (3M ESPE) (15 specimens). Group CR: Ceramic Repair N system (Ivoclar Vivadent) [grinding with diamond stone + Monobond $\mathrm{N}$ universal primer adhesive] (15 specimens). Each group was further sub-divided into three sub-groups according to the surface treatment methods: Sub-groups (CJS 3, 2,1): CoJet Sandblasting at pressure 3,2,1 bar, Sub-group (CRG): Ceramic Repair Grinding with diamond stone and Sub-groups (CRS 2,1): Ceramic Repair Sandblasting with CoJet sand at pressure 2 and1 bar. Tetric N- ceram composite resin was polymerized on each conditioned specimen. The shear bond strength was tested using a universal testing machine, and fracture sites were examined with SEM. The data of bond strengths were statistically analyzed with two-way ANOVA.

Results: No statistically significant differences in the mean shear bond strength values between Cojet Group (11.31 $\pm 0.71 \mathrm{MPa}$ ) and Ceramic Repair-N Group (11.02 $\pm 0.81 \mathrm{MPa})$. There were no statistically significant differences in the mean shear bond strength values between 1 bar treated

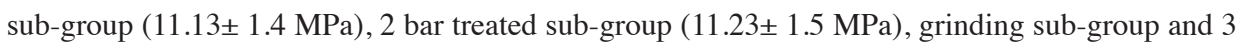
bar (control) sub-group (11.12 $\pm 1.8 \mathrm{MPa}),(\mathrm{P}>0.05)$.

Conclusion: Surface treatment of low pressure abrasion protocol or grinding following with Monobond $\mathrm{N}$ universal primer gave the similar shear bond strength values of the high pressure abrasion protocol.

\footnotetext{
*Associate Professor, Crown and Bridge Department, Faculty of Dental Medicine, Al-Azhar University.

** Crown and Bridge Department, Faculty of dental medicine, Al-Azhar University.

*** Professor, Crown and Bridge Department, Faculty of Dental Medicine, Al-Azhar University.
} 


\section{INTRODUCTION}

Zirconia-based restorations use a high strength ceramic material for the substructure to provide sufficient resistance against forces of mastication. Clinical failures of veneered zirconia frameworks due to chipping of the veneering ceramic are reported to be at $13.0 \%$ after an observation period of three years and at $15.2 \%$ after five years ${ }^{(1)}$.

In order to avoid an expensive replacement, numerous repair systems are now available to the dentist for the intra-oral repairing of ceramics. The most commonly used method is bonding composite resin materials to the fractured surface ${ }^{(2)}$.

Optimal surface preparation techniques for chemical and/or mechanical bonding to ceramic substrate are crucial to ensure clinical success when placing indirect ceramic restorations as well as when repairing them intra-orally. A variety of surface preparation techniques have been advocated which includes the use of acids, particle abrasion, adhesives, and silane coupling agents ${ }^{(3,4)}$.

Zirconia-based ceramics are highly resistant to the chemical attack of hydrofluoric acid and different approaches if clinicians elect to bond these restorations using resin-based adhesives and luting cements ${ }^{(5,6)}$.

Using high pressure particles abrasion has a bad effect on the mechanical properties of zirconia since cracks and flaws formation and transformation from the tetragonal to the monoclinic may occur, which is why authors recommend using low pressure particles abrasion ${ }^{(7)}$.

Silane coupling agents (silanes) are wellknown for forming covalent chemical bonds between dissimilar materials. Phosphate-monomercontaining agents is a new generation presented as universal primers to enhance the wetting and modify the zirconia chemistry. These primers contain silane and phosphate monomer ${ }^{(8-10)}$.
Therefore, the hypothesis of this study was that ceramic repair system and sandblasting pressure will affect the shear bond strength between zirconia and composite resin.

\section{MATERIALS AND METHODS}

Incoris ZI blocks (Sirona, Germany) with block size 40/19: 15.5 × 19 × $39 \mathrm{~mm}$ were used to obtain (30 specimens). Each specimen has a square shape with $13.3 \times 13.3 \times 3.3 \mathrm{~mm}$ dimensions. The cutting process occurred using a precision cutting instrument and diamond-coated cutting discs IsoMet 4000 microsaw Buehler, USA. After cutting the specimens, they were placed in the ultrasonic cleanser, and then dried. The Sirona infire HTC speed furnace, sintering furnace, sirona Germany. After a sintering process, the dimension of each specimen was approximately $10 \times 10 \times 2 \mathrm{~mm}$.

A total of 30 zirconia specimens were divided into two main groups according to the repairing systems: Group CJ: CoJet intra -oral repairing system (15 specimens), group CR: Ceramic Repair $\mathrm{N}$ system (15 specimens).

Each group was further sub-divided into three subgroups according to the surface treatment methods: sub-group (CJHS 3): CoJet High Sandblasting at pressure 3 bar ( $n=5)$,sub-group (CJAS 2): CoJet Average Sandblasting at pressure 2 bar $(n=5)$,subgroup (CJLS 1): CoJet low Sandblasting at pressure 1 bar ( $n=5)$,sub-group (CRG): Ceramic Repair Grinding with diamond stone $(\mathrm{n}=5)$,sub-group (CRAS 2): Ceramic Repair Average Sandblasting at pressure 2 bar ( $\mathrm{n}=5$ ), sub-group (CRLS 1): Ceramic Repair Low Sandblasting at pressure 1 bar $(n=5)$.

Specially designed Teflon moulds were fabricated in the present study in order to standardize the dimensions and positions of the repair composite discs.

Mould (Z): It consisted of an inner Teflon mould, square in shape, with a central hole of $(10 \times 10 \times 2)$ $\mathrm{mm}$, which holds the zirconia specimens. 
Mould (C): It consisted of an inner splitted Teflon mould, circular in shape, with a central hole of 6 $\mathrm{mm}$ diameter, $4 \mathrm{~mm}$ length $\mathrm{mm}$, circular in shape which holds the composite material, which is placed directly above the mould $(Z)$, while its central hole is placed directly above the center of the zirconia specimen. An outer stabilizing ring was fabricated for the whole assembly of the moulds together.

To standardize the distance between the nozzle of the micoblaster and the special holder was fabricated. It consists of three parts attached to each other. The first part is a holder fabricated from wood to hold the zirconia specimen, the second part is a metal ring to hold the microblaster and fix it with two screws, and the third part is a metal arm to hold the first and second parts together in order to achieve a perpendicular relationship between the nozzle of the microblaster and the center of zirconia specimens (figure1).

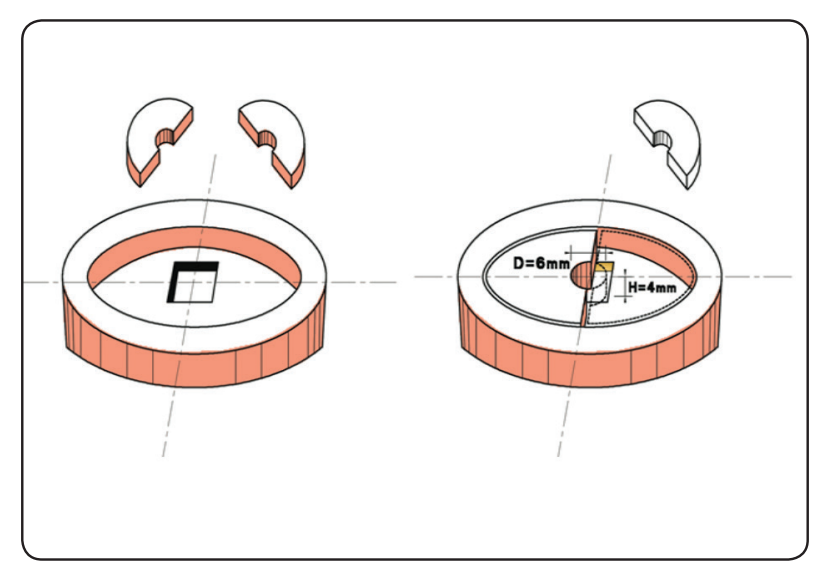

Fig. (1): A diagram showing moulds assembly within the ring.

\section{Application of zirconia repairing systems:}

All sub-groups, except Ceramic Repair Grinding (CRG), were subjected to sandblasting using the intraoral microblaster with Cojet sand (30 $\mu \mathrm{m}$ aluminum particles modified with silica) for 15 seconds at a fixed distance of $(10 \mathrm{~mm})$. The microblaster was attached to a

\section{Application of CoJet intraoral repairing system $(n=15)$ :}

The specimens of all sub-groups of CoJet system group were subjected to CoJet sandblasting as follows: (CJHS 3): CoJet High Sandblasting at pressure 3 bar ( $\mathrm{n}=5$ ), sub-group (CJAS 2): CoJet Average Sandblasting at pressure 2 bar $(n=5)$, and sub-group (CJLS 1): CoJet low Sandblasting at pressure 1 bar $(n=5)$.

After sandblasting, the specimens were rinsed with a water spray for 30 seconds to clean the surface from the residual sand particles, and then dried with oil-free air. The specimens were treated with a prehydrolyzed silane-based primer (RelyX ${ }^{\mathrm{TM}}$ Ceramic Primer) and then dried with oil-free air for 30 seconds. A bonding agent (Adper ${ }^{\mathrm{TM}}$ Single Bond 2 Adhesive) was used to apply a thin layer with a disposable brush and then light cured for 10 seconds.

\section{Application of Ceramic repair $N$ system $(n=15)$ :}

In Ceramic Repair N group, (CRG) sub-group according to the manufacturer's instruction were subjected to grinding and roughening using a diamond stone $(n=5)$ (figure 19), while (CRAS) was subjected to sandblasting with cojet sand at pressure 2 bar $(n=5)$ and (CRLS) was subjected to sandblasting with cojet sand at pressure $1 \mathrm{bar}(\mathrm{n}=5)$. After sandblasting, the specimens were rinsed with a water spray then dried with oil-free air, and then Monobond $\mathrm{N}$ was applied on the zirconia specimens and allowed to react for 60 seconds, then dried with oil-free air.

According to the manufacturer's instructions, a thin layer of bonding agent (Heliobond) was applied, then light cured for 10 seconds.

After surface treatment and application of the bonding agents, the light cure nano-hybrid composite Tetric N-ceram was applied on all specimens inside the mould (c) increment by increment, the maximum increment depth is $2 \mathrm{~mm}$, and light cured for each layer for 10 second, and the moulds were removed. 
Each specimen was then mounted in the universal testing machine (Model LRX-plus; Lloyd Instruments Ltd., Fareham, UK). Equipped with a load cell of $5 \mathrm{kN}$ at cross-head speed of $0.5 \mathrm{~mm} / \mathrm{min}$ and data were recorded using computer software (Nexygen-MT; Lloyd Instruments) until failure occurred. The mode of failure was classified as either cohesive failure in the composite resin, or interfacial adhesive failure at the zirconia-resin interface.

\section{RESULTS}

\section{Effect of repairing systems:}

Regardless to surface treatment pressure, totally it was found that CoJet group recorded statistically non-significant $(\mathrm{P}>0.05)$ higher shear bond strength mean value $(11.31 \pm 0.71 \mathrm{MPa})$ than ceramic repair group (11.02 $\pm 0.81 \mathrm{MPa}$ ) as indicated by two-way ANOVA test. Table (1) and Figure (2).

TABLE (1): Comparison between total shear bond strength results (Mean values \pm SDs) as function of repair system

\begin{tabular}{|c|c|c|c|c|}
\hline \multicolumn{2}{|c|}{ Variable } & Mean & SD & $\begin{array}{c}\text { Statistics } \\
\text { (P value) }\end{array}$ \\
\hline \multirow{2}{*}{$\begin{array}{c}\text { Repair } \\
\text { system }\end{array}$} & Cojet & 11.31 & 0.71 & \multirow{2}{*}{$0.7195 \mathrm{~ns}$} \\
\cline { 2 - 4 } & Ceramic repair & 11.02 & 0.81 & \\
\hline
\end{tabular}

Different letter in the same column indicating statistically significant difference $(p<0.05)(p<0.05) S$; Significant $(p<$ $0.05)$ NS; Non-Significant $(p>0.05)$

\section{Effect of surface treatment pressure:}

Regardless to repair system, totally it was found that 2 bar treated subgroup recorded statistically non-significant $(\mathrm{P}>0.05)$ highest shear bond strength mean value (11.23 $\pm 1.5 \mathrm{MPa})$ followed by 1 bar treated sub group $(11.13 \pm 1.4 \mathrm{MPa})$ then while control subgroup recorded statistically nonsignificant $(\mathrm{P}>0.05)$ lowest shear bond strength mean value $(11.12 \pm 1.8 \mathrm{MPa})$ as indicated by twoway ANOVA test. Table (2) and Figure (3).
TABLE (2) Comparison between total shear bond strength results (Mean values \pm SDs) as function of surface treatment pressure

\begin{tabular}{|c|c|c|c|c|}
\hline \multicolumn{2}{|c|}{ Variables } & Mean & SD & $\begin{array}{c}\text { Statistics } \\
\text { (p-value) }\end{array}$ \\
\hline \multirow{2}{*}{$\begin{array}{c}\text { Surface } \\
\text { treatment } \\
\text { pressure }\end{array}$} & Control & 11.12 & 1.8 & \\
\cline { 2 - 4 } & $\mathbf{2}$ bar & 11.23 & 1.5 & \multirow{2}{*}{$0.9923 \mathrm{~ns}$} \\
\cline { 2 - 4 } & $\mathbf{1}$ bar & 11.13 & 1.4 & \\
\hline
\end{tabular}

Different letter in the same column indicating statistically significant difference $(p<0.05) S$; Significant $(p<0.05)$ NS; Non-Significant $(p>0.05)$

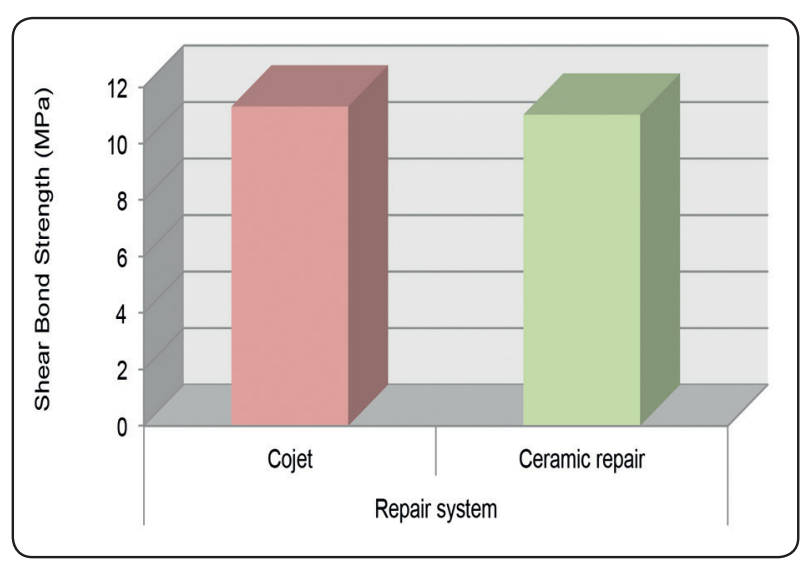

Fig. (2): Effect of repair system

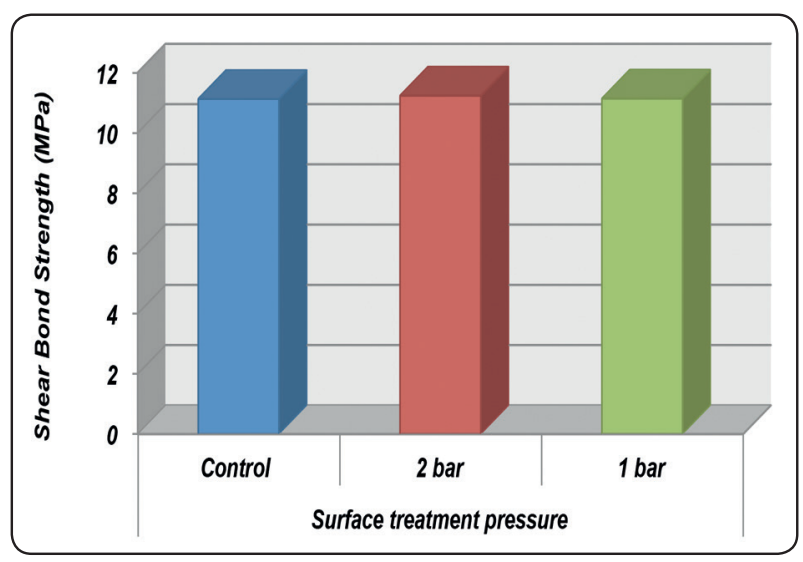

Fig. (3): Effect of surface treatment pressure 


\section{DISCUSSION}

The increase of patients' desire for esthetics has resulted in the use of ceramic restorations in the anterior region as well as the posterior region. The acceptance of ceramic restorations has increased because of their inherent esthetics, excellent biocompatibility, and improved physical properties ${ }^{(11-14)}$.

A weak bond between the veneering porcelain and zirconia core can result in the fracture or delamination of the veneer itself. According to a study by Sailer et al., the clinical failure rate caused by chipping of the veneering porcelain was reported to be at $13 \%$ after three years and at $15.2 \%$ after five years ${ }^{(15-18)}$.

Cojet $^{\mathrm{TM}}$ System was used in the present study as many authors recommended the use of this system to improve the bond strength of composite resin to zirconia through the embedding of silica particles in the zirconia surface which makes a micromechanical pore in zirconia, followed by silane coupling agent to make a chemical bond between zirconia and $\operatorname{resin}^{(19-21)}$.

Ceramic Repair N System was the other repairing system used in the present study to compare it with Cojet system and evaluate its effect on the shear bond strength in case of combination with Monobond plus universal primer which contains both an MDP monomer and a silane monomer 3-MPS, which creates a durable bond strength to zirconia ${ }^{(22,23)}$.

In addition, the sandblasting pressure was decreased in to 2 bar, and to 1 bar, since many authors recommended the use of low air pressure in sandblasting of the zirconia to avoid micro flaws and cracks creation which decreases the mechanical properties of zirconia and also may cause phase transformation of zirconia from the tetragonal to the monoclinic phase ${ }^{(24) .}$

The hypothesis of this study was that ceramic repair system and sandblasting pressure will affect the shear bond strength between zirconia and composite resin. This hypothesis was rejected.
The results showed that there were no statistically significant differences in the mean shear bond strength values between Cojet Group and Ceramic Repair Group ( $\mathrm{P}>0.05)$. These results are in agreement with the results of Yong J. J. et al. (2015) ${ }^{(17)}$.

The minimum acceptable value of the shear bond strength is $10-13 \mathrm{MPa}$. If the value was greater than $13 \mathrm{MPa}$ between the zirconia and the composite, the cohesive failure occurs. In the present study, the values of shear bond strength are within this limit, which led to the adhesive failure. However, many studies recorded values more than this range but with different methodologies ${ }^{(25)}$.

The chemical components of the zirconia (traces such as $\mathrm{Li} 2 \mathrm{O}, \mathrm{Na} 2 \mathrm{O}, \mathrm{K} 2 \mathrm{O}, \mathrm{CaO}, \mathrm{MgO}$ ) are bound to each other by strong covalent bonds with hydroxyl groups at the zirconia surface. When the surface is air abraded, this would generate more hydroxyl groups on the surface and also enhances the micromechanical retention ${ }^{(26-29)}$.

The silane molecules react with water forming silanol groups (-Si-OH) from methacryloxy groups (-Si-O-CH3). Silanol groups react with the silica deposited on the zirconia surface to form a siloxane network (-Si-O-Si-O-). The monomeric ends of the silane react with the methacrylate groups of the resin material ${ }^{(30-32)}$.

The results showed that there were no statistically significant differences in the mean shear bond strength values between 1 bar treated sub-group, 2 bar treated sub-group, grinding sub-group, and 3 bar (control) sub-group $(\mathrm{P}>0.05)$.

These abovementioned results, which reported no significant differences between high and low sandblasting pressure, are in agreement with Kern et al. (2009), Yang B. et al. (2010) and Re D. et al. (2012) $^{(33,34,35)}$.

The limitations of the present study are that its procedures were done outside the mouth (Invitro) on discs, not on restorations and in absence of oral conditions such as: saliva or masticatory forces. Another shortage in the present study is the use of one type of composite resin. 


\section{CONCLUSION}

Surface treatment of low pressure abrasion protocol or grinding following with Monobond $\mathrm{N}$ universal primer gave the similar shear bond strength values of the high pressure abrasion protocol.

\section{REFRENCES}

1- Dawood R M, Ibraheem A F. Evaluation of shear bond strength of zirconia to tooth structure after different zirconia surface treatment techniques. J Bagh Coll Dentistry 2015; 27(1):77-85.

2- Miyazaki T, Nakamura T, Matsumura H, Ban S, Kobayashi T. Current status of zirconia restoration. J Prosthodont Res. 2013 Oct;57(4):236-61.

3- Saridag S., Tak O., Alniacik G. Basic properties and types of zirconia: An overview. World J Stomtol. 2013;2(3): $40-47$.

4- Elie E and Daou. The Zirconia Ceramic: Strengths and Weaknesses. The Open Dentistry Journal.2014; 8:33-42.

5- Khamverdi Z. and Moshiri Z. Zirconia: An Up-to-date Literature Review. Avicenna Journal of Dental Research. 2013;4(1): 1-15.

6- Faeizah N., Muchtar A., Yahya N. and Jameelah M. A Review of Zirconia as a Dental Restorative Material. Australian Journal of Basic and Applied Sciences. 2012 6;(12): 9-13.

7- Komine, F, Blatz M B. and Matsumura H. Current status of zirconia-based fixed restorations. Journal of Oral Science. 2010;52(4) :531-39.

8- Salimi H ,Mosharraf R, and Savabi O.Effect of framework design on fracture resistance of zirconium oxide posterior fixed partial dentures. Dent Res J (Isfahan). 2012 NovDec; 9(6): 764-769.

9- Mahmood DJ, Linderoth E H, Wennerberg Ann, and Steyern $\mathrm{P}$ V V. Influence of core design, production technique, and material selection on fracture behavior of yttria-stabilized tetragonal zirconia polycrystal fixed dental prostheses produced using different multilayer techniques: split-file, over-pressing, and manually built-up veneers. Clin Cosmet Investig Dent. 2016; 8: 15-27.

10- Jang GW, Kim HS and Choe HC,Son MK .Fracture strength and mechanism of dental ceramic crown with zirconia thickness. Procedia Engineering.2011;10:1556-60.
11- Sun T., Zhou S.,Lai R., Liu R., Ma S., Zhou Z. and Longquan S. Load-bearing capacity and the recommended thickness of dental monolithic zirconia single crowns. J. Mech Behav Biomed Mater. 2014; 35: 93-101.

12- Zhang Y. Making yttria-stabilized tetragonal zirconia translucent. Dent Mater.October 2014;30:(10)1195-1203.

13- Han IH., Kang DW., Chung CH., Choe HC. and Son MK. Effect of various intraoral repair systems on the shear bond strength of composite resin to zirconia. J Adv Prosthodont. 2013 Aug;5(3):248-55.

14- Casucci A., Monticelli F., Goracci C., Mazzitelli C., Cantoro A., Papacchini F. and Ferrari M. Effect of surface pre-treatments on the zirconia ceramic-resin cement microtensile bond strength. Dent Mater. 2011; 27:1024-30.

15- Kim BK., Bae HE., Shim JS. and Lee KW. The influence of ceramic surface treatments on the tensile bond strength of composite resin to all-ceramic coping materials. J Prosthet Dent. 2005; 94:357-62.

16- Antonio BM., Felipe VL., Roberto S. and Leonardo B. Effect of surface treatments on the resin bond to zirconiumbased ceramic. Int J Prosthodont.2005;18(1)60-65.

17- Yong J J., Cheol C H., Heon C C., Wan K D. and Kyoung S. Effect of Various Surface Treatments on the Bond Strength Between Composite Resin and Zirconia Veneering Ceramic. Science of Advanced Materials. 2015;7(6)57-62.

18- Shin YJ., Shin Y., Yi YA., Kim J., Lee IB., Cho BH., Son HH. and Seo DG. Evaluation of the shear bond strength of resin cement to Y-TZP ceramic after different surface treatments scanning,2014 Sep-Oct;36(5):479-86.

19- Kirmali O., Kapdan A., Harorli OT., Barutcugil C. and Ozarslan MM. Efficacy of ceramic repair material on the bond strength of composite resin to zirconia ceramic. Acta .Odontologica Scandinavica .2015;73(1):28-32.

20- Zandparsa R., Talua NA., Finkelman MD. and Schaus SE. An in vitro comparison of shear bond strength of zirconia to enamel using different surface treatments. J Prosthodont.2014 Feb;23(2):117-23.

21- Tanış MS., Akay C and Karakış D. Resin cementation of zirconia ceramics with different bonding agents. Biotechnol Equip.2015;29(2):363-367.

22- 'Attia A. Bond strength of three luting agents to zirconia ceramic - Influence of surface treatment and thermocycling. J Appl Oral Sci. 2011 Jul-Aug;19(4):388-95. 
23- Sailer I, Fehér A, Filser F, Gauckler LJ, Lüthy H, Hämmerle $\mathrm{CH}$. Five-year clinical results of zirconia frameworks for posterior fixed partial dentures. Int J Prosthodont. 2007; 20:383-88.

24- Reddy S M., Vijitha D., Deepak T., Balasubramanian R., and Satish A. Evaluation of Shear Bond Strength of Zirconia Bonded to Dentin After Various Surface Treatments of Zirconia. J Indian Prosthodont Soc.2014 Mar; 14(1): $38-41$.

25- An HS, Park JM, Park EJ. Evaluation of shear bond strengths of gingiva-colored composite resin to porcelain, metal and zirconia substrates. J Adv Prosthodont.2011S ep;3(3):166-71.

26- Amaral R, Ozcan M, Valandro LF, Balducci I, Bottino MA. Effect of conditioning methods on the microtensile bond strength of phosphate monomer-based cement on zirconia ceramic in dry and aged conditions. J Biomed Mater Res B Appl Biomater. 2008 Apr;85(1):1-9.

27- Attia A. Influence of surface treatment and cyclic loading on the durability of repaired all-ceramic crowns. J Appl Oral Sci 2010;18(2):194-200.

28- Yi YA., Ahn JS., Park YJ., Jun SH., Lee IB., Cho BH., Son HH. and Seo DG. The effect of sandblasting and different primers on shear bond strength between yttria-tetragonal zirconia polycrystal ceramic and a self-adhesive resin cement.Oper Dent.2015;40(1):63-71.
29- Inokoshi M., Kameyama A., De Munck J., Minakuchi S.and Van Meerbeek B. Durable bonding to mechanically and/or chemically pre-treated dental zirconia. J Dent. 2013 Feb; 41(2):170-9.

30- Inokoshi M., Poitevin A., De Munck J., Minakuchi S. and Van Meerbeek B. Bonding effectiveness to different chemically pre-treated dental zirconia. Clin Oral Investig. 2014;18(7):1803-12.

31- Atsu SS., Kilicarslan MA., Kucukesmen HC. And Aka PS .Effect of zirconium-oxide ceramic surface treatments on the bond strength to adhesive resin. J Prosthet Dent. 2006;95(6):430-6.

32- Sanohkan S., Kukiattrakoon B., Larpboonphol N., Sae-Yib T., Jampa T. and Manoppan S. The effect of various primers on shear bond strength of zirconia ceramic and resin composite.J Conservative Dentistry.2013;16:499-502.

33- Re D., Augusti D., Augusti G. and Giovannetti A. Early bond strength to low-pressure sandblasted zirconia: evaluation of a self-adhesive cement. Eur J Esthet Dent. 2012;7(2):164-75.

34- Kern M.,Barloi A. and Surface conditioning influences zirconia ceramic bonding. J Dent Res. 2009 Sep;88(9): 817-22.

35-Yang B., Barloi A. and Influence of air-abrasion on zirconia ceramic bonding using an adhesive composite resin. Dent Mater. 2010 Jan;26(1):44-50. 